\title{
A Fatigue Life Experiment for Aerospace Engineering Undergraduates
}

\section{Dr. David C. Fleming, Florida Institute of Technology}

David C. Fleming is an Associate Professor of Aerospace Engineering at the Florida Institute of Technology, in Melbourne, FL. He earned his S.B. degree in Aeronautics and Astronautics from the Massachusetts Institute of Technology in 1989, and M.S. and Ph.D. degrees in Aerospace Engineering from the University of Maryland, College Park, in 1991 and 1995, respectively. His research is in the area of composite structures, including an emphasis on application to crashworthy structures. He received the Kerry Bruce Clark award for Excellence in Teaching, Florida Tech's highest teaching award, for the 2013-2014 academic year. 


\title{
A Fatigue Life Experiment for Aerospace Engineering Undergraduates
}

\begin{abstract}
The importance of fatigue in aerospace structural design suggests the need for this topic to be addressed as part of aerospace engineering undergraduate curricula. This paper describes a sequence of laboratory experiments for upper level aerospace engineering students that emphasizes stress concentrations and their role in quasistatic and fatigue loading. The fatigue experiment is conducted with a servohydraulic testing machine using simple specimens. Results of the experiment generated over several years of implementation are presented. A survey of students taken before and after completing the course shows that graduates of the course have a significantly improved understanding of stress concentration effects and their influence on the stress field. These students also have a significantly increased awareness of the importance of fatigue in engineering practice.
\end{abstract}

\section{Introduction}

In a 2002 investigation of failure modes in structures, Findlay and Harrison ${ }^{1}$ reported that $31 \%$ of failures in general engineering components are attributable to fatigue issues (including corrosion fatigue) while only $11 \%$ are due to simple mechanical overload. For the case of aircraft structures, the significance of fatigue is even more dramatic: $62 \%$ of failures are reported as fatigue-related and only 14\% due to overload. Examples of disasters in aerospace engineering resulting from fatigue issues abound. The most famous example is the de Havilland Comet, the first commercial jet transport aircraft in service, which suffered in-flight disintegrations in the 1950s due to premature fatigue growth in the fuselage hastened by stress concentrations around windows and hatches. ${ }^{2}$ Subsequently, the problems with the Comet were identified and a modified version of the aircraft was developed and successfully operated. Still fatigue continues to be a bane of aeronautical engineering. Aging aircraft issues were brought to the forefront due to the Aloha airlines accident in 1988 in which a Boeing 737 lost a significant part of its fuselage skin during flight due to fatigue crack growth. ${ }^{3}$ The aircraft landed safely though an unrestrained flight attendant was ejected from the aircraft and killed. More recently, in 2007 an F-15C broke apart in flight during a training flight in Missouri. This accident was found to result from fatigue failure in a longeron resulting from a manufacturing defect. ${ }^{4}$ A search of the National Transportation Safety Board (NTSB) aviation accident reports for the calendar year 2014 shows nine probable cause reports for which fatigue is identified as part of a probable major contributing factor of aviation incidents/accidents. ${ }^{5}$ Of these cases, six were in engines or related systems, while three were in the landing gear.

The prevalence of fatigue as a major factor in real-world aircraft accidents and incidents, however, is in marked contrast to the attention that this subject receives in many undergraduate aerospace engineering programs. A review of fatigue content in top five (as ranked by the latest 
US News \& World Report Ranking) US aerospace engineering programs offering full undergraduate degrees in aerospace engineering or similarly named programs was made. Curricula were evaluated based on course descriptions, statements of course outcomes and objectives and other materials published on university websites. This review showed that only three out of five of these programs identified the topic of fatigue among the required aerospace

engineering course work and none of these five identified fatigue among the required aerospace laboratory coursework. (Fatigue may have been included among materials science curricula in these programs.) This level of coverage of fatigue is consistent with textbooks in use in aerospace engineering programs. The structural mechanics portion of a typical curriculum typically includes a course on topics that fall under the heading of "Mechanics of Materials" followed by a more specialized aerospace structural analysis course that primarily covers stress analysis of thin-walled structures. In some curricula these courses are followed by more advanced structures classes that cover topics such as vibrations/structural dynamics and computational methods for structural analysis. A summary of the fatigue and related fracture mechanics content included in some popular Mechanics of Materials and Aerospace Structures textbooks is included in Table A1 in Appendix A. It can be seen in Table A1 that the coverage of fatigue is cursory in typical Mechanics of Materials texts. Most aerospace structures texts include some coverage of fatigue topics, but still at an elementary level.

A detailed, quantitative analysis of fatigue, requiring significant experience in techniques of elasticity and study of the subject of fracture mechanics, is beyond the scope of undergraduate students and rightly finds a place among graduate studies in Aerospace Engineering. However, the importance of fatigue in aeronautical engineering practice suggests that undergraduate students of Aerospace Engineering would benefit from even a qualitative understanding of the role of fatigue in engineering applications. While lectures on the subject could certainly be beneficial, a laboratory demonstration of fatigue has the potential to provide a more memorable experience, and therefore provide a greater impact on students' qualitative appreciation of the importance of fatigue in aerospace structures.

The theoretical framework of the present paper is that undergraduate aerospace engineering students have an insufficient appreciation of the importance of fatigue in engineering practice, and that an undergraduate laboratory to explore this subject will provide a better appreciation of fatigue among the undergraduate students and hence produce better engineers upon graduation. It was therefore the goal of this author to develop a laboratory experience to be integrated into an undergraduate aerospace engineering structures laboratory course. This experiment would emphasize the significance of stress concentrations on the fatigue life of aerospace structures. This paper describes the development of that laboratory exercise, its results, and efforts to evaluate its success in meeting the pedagogical goals of the experiment.

\section{Laboratory Sequence on Stress Concentrations and Fatigue}

The fatigue experiment described in this paper has been implemented in an undergraduate Aerospace Structures Laboratory course as part of a multi-week sequence that investigates 1) 
elastic and strength properties of aluminum alloys; 2) stress concentrations effects, their measurement, and investigation of their role in failure under quasistatic loading conditions; and 3) fatigue life of notched specimens. Stress concentration specimens used in the sequence of experiments are shown in Figures 1 and 2.

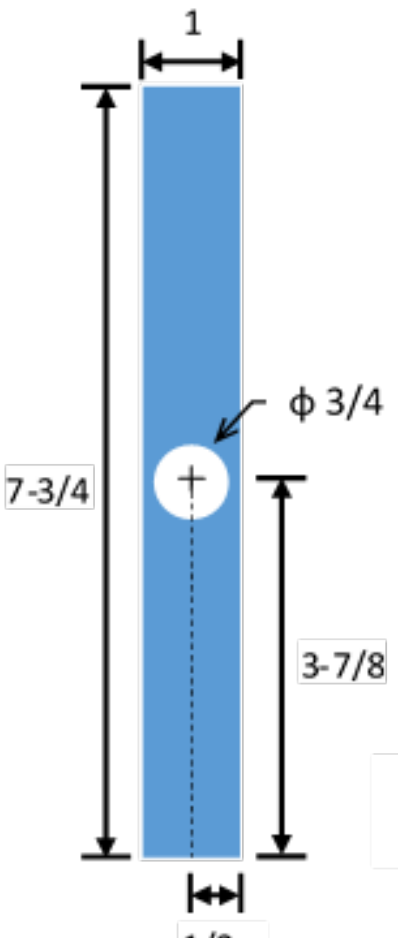

$1 / 2$

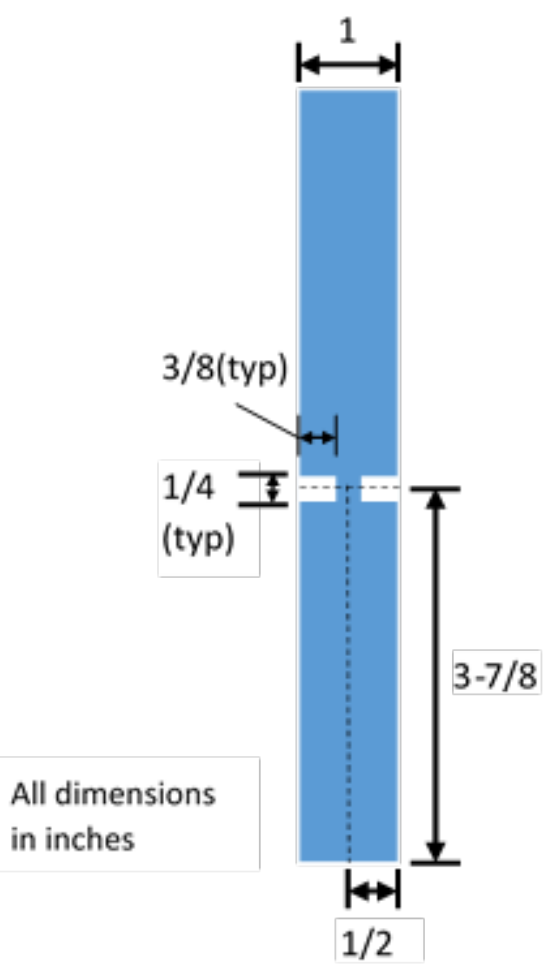

(b) Notch specimen

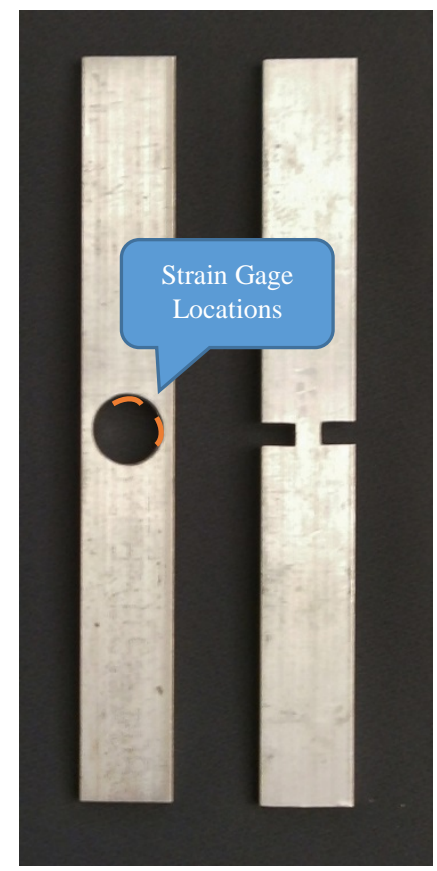

(c) photos of typical specimens

(a) Circular hole specimen

Figure 1: Dimensions of stress concentration specimens used in static and fatigue loading to failure. All specimens have uniform thickness of $1 / 4$ inch.

\section{Part 1: Dogbone Specimens and Strain Gage Installation}

In the first part of the experiment, conventional dogbone specimens of the type used in ASTM Standard E- $8^{6}$ are used with electrical resistance strain gages to determine the modulus of elasticity, the Poisson ratio, the yield strength and the ultimate strength of aluminum alloys. While students have typically already been exposed to some of these concepts in a previous materials science laboratory course, this portion of the experiment adds the following concepts:

- Installation and use of electrical resistance strain gages

- Comparison of two different aluminum alloys: the 'general purpose' 6061-T6511 and the high strength alloy 2024-T4 more typical of aerospace use. Students are often surprised by the significant strength difference between these alloys and this experiment helps reinforce the importance of material selection. 


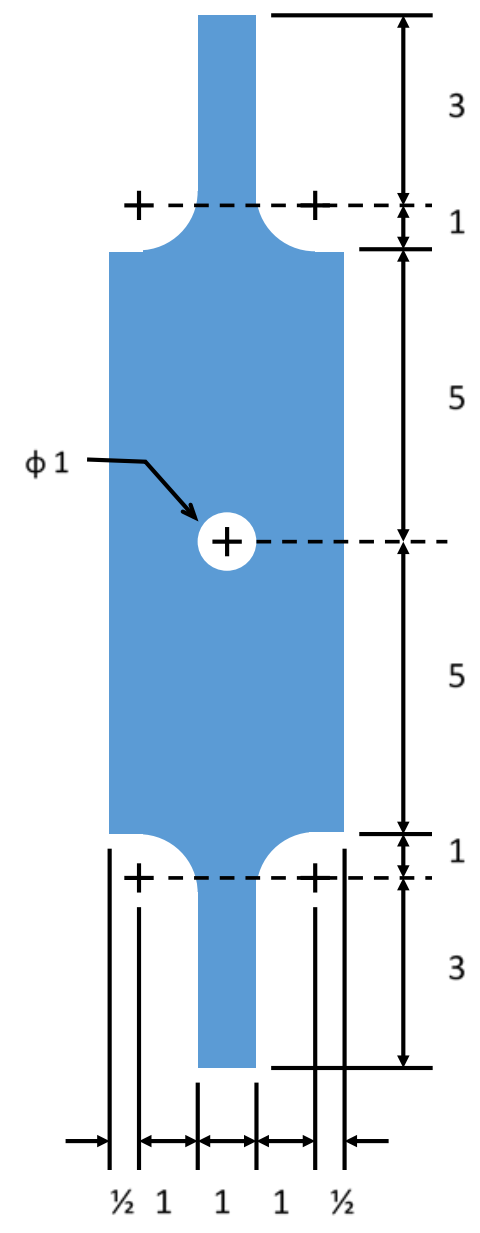

All dimensions in inches
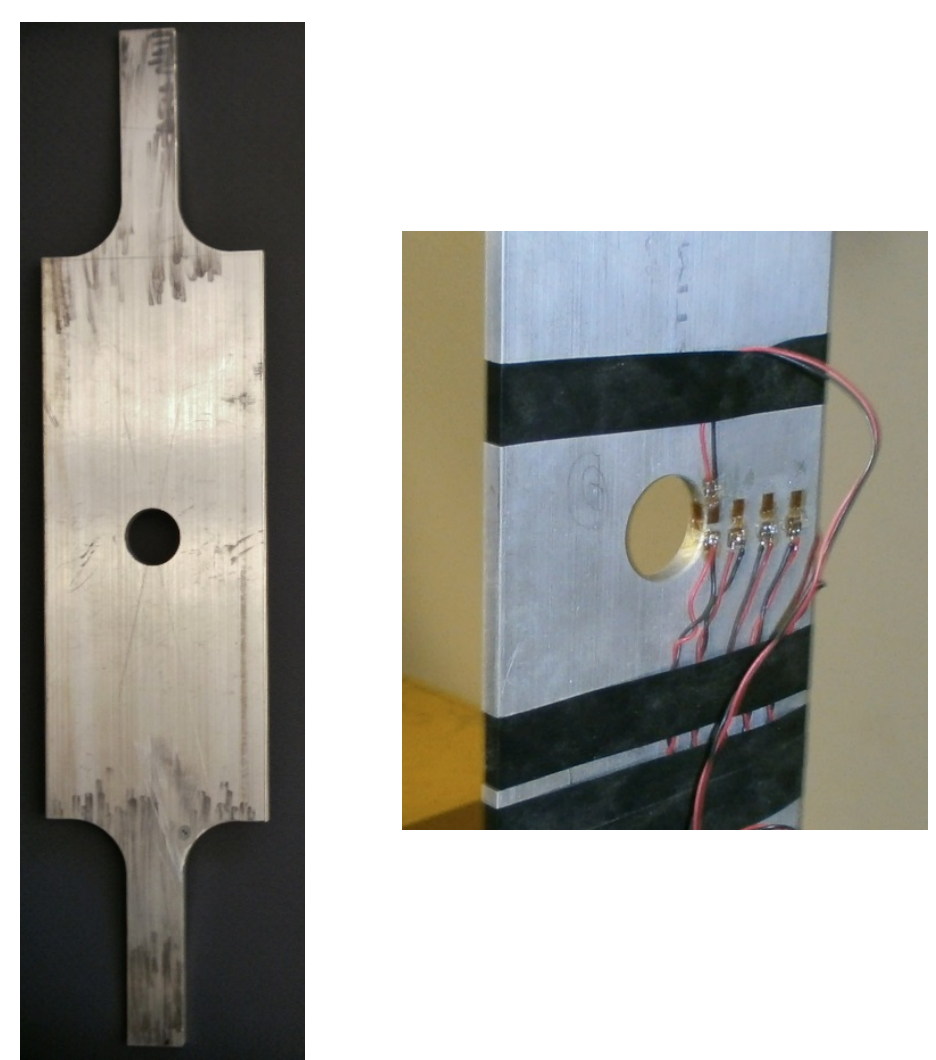

(a) dimensions

(b) prior to instrumentation

(c) following instrumentation

Figure 2: Dimensions of stress concentration specimens used to evaluate the stress distribution near a concentration. Specimen is $1 / 4$ inch thick.

\section{Part 2: Stress Concentrations under Quasistatic Loading}

The second part of the experiment investigates stress concentration factors under quasistatic loading.

- A large specimen containing a circular hole (Figure 2) is loaded in axial tension. Loads are kept low enough so that yielding does not occur and the specimen can be reused. A number of strain gages are installed across the width of the specimen starting from the inner surface of the hole to allow the stress distribution to be plotted. This allows the student to understand the localized nature of the stress concentration effect. This specimen is similar to one used by the author as a student of the Massachusetts Institute of Technology. Similar tests are commonly used in laboratory courses at many universities. 
- Two types of notched 6061-T6511 aluminum specimens are loaded in quasistatic tension to failure, those with circular holes and square notches, as shown in Figure 1.

o Circular hole notched specimens follow the dimensions of the test specimen proposed by Vishay Measurements Group ${ }^{7}$ as an experiment for measuring stress concentration factors using electrical resistance strain gages. Dimensions of the test specimen are shown in Figure1(a). Dimensions of the hole are such that it is just barely within the range of practicality to place strain gages on the inner surface of the hole. Two gages are placed inside the hole in locations noted in Figure 1(c). One allows the stress concentration factor (SCF) to be measured. (From the geometry of the specimens, SCF should be about 2.05 for these specimens. ${ }^{7}$ ) The second strain gage is placed at the top of the hole, and shows compressive strain during the test. This measurement emphasizes for students that the stress field is affected in three dimensions around the vicinity of the notch and that the single measurement of the SCF does not 'tell the whole story' about stress concentration effects.

o Dimensions of the square notch specimens (Figure 1(b)) are selected so that the nominal cross-sectional area is the same as for the circular hole specimens. While direct measurement of the SCF is not possible with these specimens, theoretical considerations suggest that the SCF for these notched specimens is considerably larger than for the circular hole specimens.

Because the specimens are made of a ductile material, plastic deformation alleviates the effective stress concentrations by the time of ultimate failure. ${ }^{8}$ Because the minimum cross-section area is the same in the two specimen types, the failure load is essentially the same for each, facilitating comparison, despite the significant difference in their stress concentration factors. Students are often very surprised by the comparison between the two specimen types even though they have received previous theoretical instruction in both lecture and lab environments, and despite their being required to submit a pre-laboratory assignment in advance of the experiment predicting the failure loads for these specimens. The quasistatic failure part of this experiment is intended to alleviate this misconception. Survey results shown in a following section evaluate their retention of the relevant concept following the experiment.

If this sequence of experiments ended following quasistatic testing, these aerospace students would have 'learned' a dangerous lesson. They have just seen a demonstration that stress concentration effects do not matter. Failure load is unaffected by stress concentrations. However, there are two important caveats. First, the result depends on the nature of the material in use. If a similar experiment were repeated with brittle materials in place of the ductile aluminum alloy, the quasistatic failure load would in fact be reduced in proportion to the SCF. ${ }^{8}$ Second, when the loading condition is changed to cyclic loading, the results are opposite and SCF is critical to the response. This is the subject of the concluding week of the laboratory exercise. 


\section{Part 3: Fatigue Life and Stress Concentrations}

In the final week of the experiment, the notched test specimens shown in Figure 1 are again used. Specimens of each type are loaded cyclically under load control using a servohydraulic testing machine and the number of cycles to failure are counted. Objectives of the fatigue crack growth experiment are as follows.

1. To provide students an appreciation of the significance of stress concentrations on fatigue life of structures.

2. To provide students an appreciation of the physical nature of fatigue crack growth under cyclic loading.

3. To provide students an appreciation of the tools and techniques of experimental techniques used in research and industry, particularly servo-controlled testing devices. This includes a basic understanding of the nature of feedback control devices, including concepts such as load control.

A deep quantitative analysis of fatigue processes in not expected at the level of this course. The intent is to provide an appreciation for the importance of fatigue in aerospace engineering, and a qualitative understanding of the importance of stress concentrations in fatigue life. A stark difference in fatigue life is observed between the two specimens when loaded in fatigue, demonstrating the significance of stress concentrations on fatigue life. The experiment also provides the opportunity to discuss various issues in fatigue crack initiation and propagation such as the importance of surface finish and variability in results due to local defects.

Development of the experiment required consideration of equipment as well as practical considerations pertaining to implementation in the existing undergraduate laboratory framework. It was desired to use available laboratory equipment (no specialized test equipment to be manufactured for the experiment). This required the use of an existing servohydraulic testing machine, common to many research laboratories, as shown in Figure 3. A benefit of using this equipment is that it gives students exposure to standard testing equipment used in engineering practice, though it does impose a burden on scheduling to ensure availability. Use of the same specimen geometry as in the quasistatic testing portion of the exercise facilitates comparison with those previous results and is beneficial due to the simplicity of manufacturing the test specimens. Due to the notch geometry, no special considerations are required with respect to gripping. Figure 3 demonstrates the ease of installing test specimens in the machine. Specimens are simply machined from 1 inch wide bar stock, leaving mill finish on the edges. Notch specimens are manufactured using a simple end mill procedure, with multiple specimens produced in a single operation. Deburring of the circular hole specimens is essential to protect fingers during the strain gage installation on the static specimens.

Because the experiment is designed to provide only a one-to-one comparison in fatigue life between specimens made from the same material that have difference notch geometries, the specific details of the test profile are not significant provided that the two specimens are subject to the same loading profile, especially the range of nominal stress levels. The key concern is to 
fit the experiment into the scheduled $2 \frac{1}{2}$ hour meeting times while leaving time for theoretical discussions, explanations of the operation of the equipment and post-testing review. Thus, the tests are run at relatively high stress levels at testing frequencies near the limits of the capacity of the machine. The testing machine is pre-programmed to execute constant amplitude loading under load control conditions.

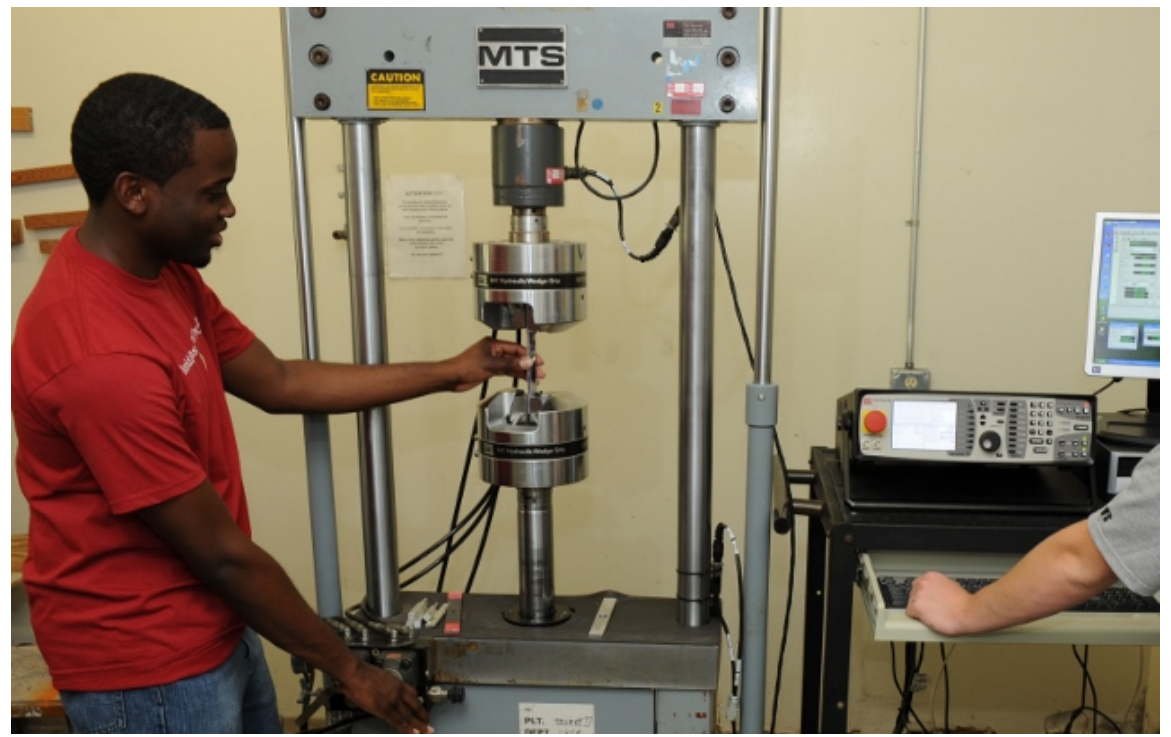

Figure 3: Installation of fatigue test specimen in servohydraulic testing machine

Results for fatigue life in general strongly depend on the load levels experienced. Given the time limitations, a single load range is used for all test samples. (In a materials rather than a structures lab, variations in fatigue life due to different stress amplitudes can be explored in the context of a rotating beam test to generate a S-N curve.) The peak amplitude of stress was set to provide an estimated run time of about 30 minutes for the specimens with a circular hole. This resulted in a maximum load of $1788 \mathrm{lb}(7.95 \mathrm{kN})$, corresponding to a nominal maximum stress of $28.6 \mathrm{ksi}$ (198 MPa). This value of nominal stress remains below the yield strength of $40.0 \mathrm{ksi}$ (276 MPa) for the aluminum alloy in use, though it is expected that plastic deformation will occur near the points of maximum stress concentration in both specimen types. ${ }^{8}$

Regarding the frequency of the cyclic loading, the direct specimen-to-specimen comparison required by the lab experiment requires only that the two specimens be tested at the same frequency. It is generally accepted, however, that fatigue life results in engineering metals are typically unaffected by testing frequency for loading rates between $10^{-2}$ and $10^{2} \mathrm{~Hz}^{9}$, which includes the range of frequencies that would be expected for standard servohydraulic testing machines such as the one in use in this experiment. The practice followed for this experiment was to run the machine near its maximum frequency. The frequency that a servoydraulic testing machine can operate at depends on the size of its hydraulic power unit (HPU) and its hydraulic service manifold, including is servovalves. In addition, it also depends on test parameters. A test requiring large displacement of the actuator will have a lower maximum frequency than one 
requiring small displacements. Information on system performance is provided by the testing machine manufacturer in the form of 'performance curves,' such as the one from MTS Systems Corporation shown in Figure 4 covering the machine in use in this experiment. Because the expected specimen displacement is about 0.012 inches $(0.3 \mathrm{~mm})$, we see that the maximum frequency is about $30 \mathrm{~Hz}$. To leave a margin, while still allowing the test to complete during the available time, a frequency of $20 \mathrm{~Hz}$ was selected for the experiment. Results, shown in Table 1, indicate that these high load levels are near the limits typically associated with low cycle fatigue. The minimum load is set to be $100 \mathrm{lb}(445 \mathrm{~N})$, resulting in an R-ratio (the ratio of the minimum to the maximum load) of 0.06. Essentially this is 'zero-to-maximum' loading. The slight positive R-ratio avoids the possibility of compression loading should the operator fail to properly zero the load at the beginning of the test while also ensuring that upon specimen failure the machine will not compress the broken parts. It is well known that experimental results for fatigue are subject to significant experimental scatter, far more so than for quasistatic testing. Because available time typically permits only one test specimen of each type to be tested during each laboratory section, the issue of scatter is addressed by sharing results between lab sections (typically 4-6 sections).

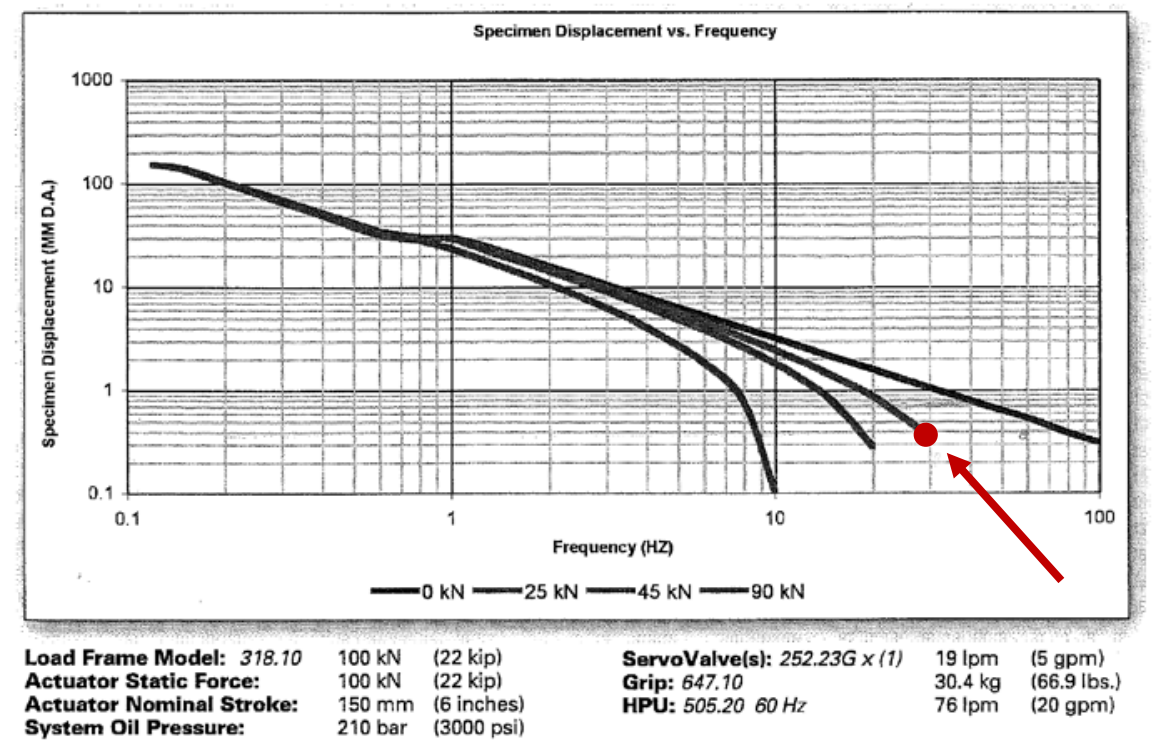

Figure 4: Performance curve used to select testing frequency, from MTS Systems Corporation (From Ref. 10).

\section{Laboratory Results}

Table 1 shows results of the fatigue portion of the experiment over the first seven years. As expected there is a significant difference, a factor of about six, between the fatigue life of the two specimens types. The scatter in the results seen in Table 2 provides an interesting lesson regarding fatigue testing. Overall, the coefficients of variation for the circular hole specimens is $33 \%$, and the coefficient of variation for the notched specimens is above $40 \%$. This is 
characteristic of fatigue crack growth behavior, where scatter in experimental data is much greater than for quasistatic testing. It is important for students to understand the fact that there is much greater uncertainty in predicting fatigue life of a structure than the static strength. It is also interesting to note the systematic differences in the response from year to year. This is attributable to variations in specimen machining. For the square notch specimens, the sharpness of the square notch (and hence the magnitude of the stress concentration) depends on the quality of the tool used. For the circular hole specimens, the surface roughness of the inside of the hole (whether there are tool marks, for example) is also variable from year to year due to variations in the tool and the feed rate used to make the hole. Post-test examination of the fracture surfaces illustrates the difference in behavior between slow crack propagation under cyclic loading and ductile failure upon final collapse of the test specimens, as shown in Figure 5.

Table 1: Summary fatigue life results across seven years

\begin{tabular}{|c|c|c|c|c|c|c|c|}
\hline \multicolumn{4}{|c|}{ Circular Hole } & \multicolumn{4}{c|}{ Square Notches } \\
\hline Year & $\begin{array}{c}\text { Number } \\
\text { of } \\
\text { Specimens }\end{array}$ & $\begin{array}{c}\text { Median } \\
\text { Cycles to } \\
\text { Failure }\end{array}$ & $\begin{array}{c}\text { Standard } \\
\text { Deviation }\end{array}$ & Year & $\begin{array}{c}\text { Number } \\
\text { of } \\
\text { Specimens }\end{array}$ & $\begin{array}{c}\text { Median } \\
\text { Cycles to } \\
\text { Failure }\end{array}$ & $\begin{array}{c}\text { Standard } \\
\text { Deviation }\end{array}$ \\
\hline 2009 & 7 & 30,000 & 7,323 & 2009 & 6 & 6,050 & 2,117 \\
\hline 2010 & 6 & 31,100 & 2,802 & 2010 & 6 & 12,400 & 1,974 \\
\hline 2011 & 5 & 40,300 & 8,975 & 2011 & 5 & 6,000 & 587 \\
\hline 2012 & 5 & 38,200 & 7,814 & 2012 & 5 & 5,050 & 703 \\
\hline $2013^{*}$ & 2 & 38,700 & -- & $2013^{*}$ & 2 & 4,900 & -- \\
\hline 2014 & 4 & 34,700 & 10,700 & 2014 & 4 & 5,400 & 171 \\
\hline 2015 & 5 & 53,200 & 7,845 & 2015 & 5 & 5,200 & 865 \\
\hline Overall & $\mathbf{3 4}$ & $\mathbf{3 3 , 3 0 0}$ & $\mathbf{1 1 , 0 7 8}$ & Overall & $\mathbf{3 3}$ & $\mathbf{5 , 7 5 0}$ & $\mathbf{2 , 7 0 0}$ \\
\hline
\end{tabular}

${ }^{*}$ Limited amount of data available for 2013 due to equipment failure

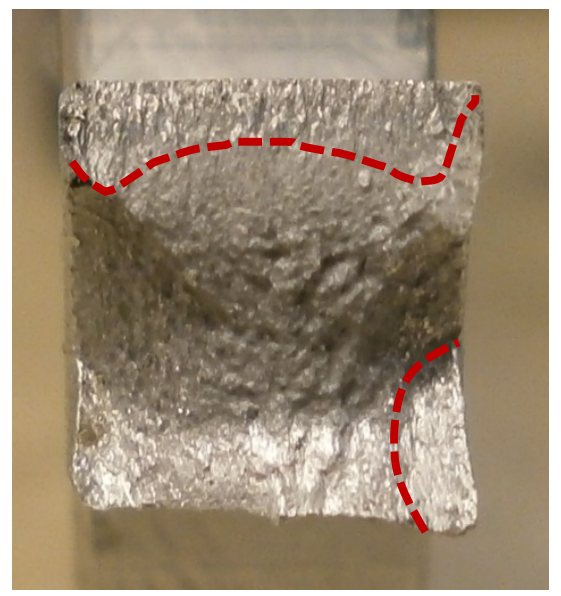

Figure 5: Failure surface of square notch fatigue specimen showing regions of fatigue crack growth and ductile collapse 


\section{Evaluation of Laboratory Exercise}

To evaluate the effectiveness of the sequence of experiments in meeting the objectives of enhancing students' appreciation of the importance of fatigue in aerospace engineering, their understanding of the phenomenon of stress concentrations, and the significance of stress concentrations in fatigue behavior, a survey was conducted. The survey questions were generated based on principles outlined by Fink. ${ }^{11}$ Given the limited pool of respondents available, it was not possible to validate the survey through pilot testing. The full set of survey question is included in Appendix B. The survey was administered to two cohorts of students. The first group were students entering their first day of classes in the aerospace structures course associated with the lab. This group is designated the 'before' group. These students have completed undergraduate course work in introductory aerospace engineering, mechanics of materials, and materials science but have not yet received specific instruction in aerospace structures. There were 70 respondents in this category. The second group was surveyed in the beginning week of “Aerospace Design 2" and includes students who have previously completed both design of aerospace structures and aerospace structures lab courses. In the large majority of cases the courses were completed seven months prior to taking the survey, but a couple of these students had finished the course a year or more before taking the survey. This group is designated the 'after' group and included 36 respondents.

After some introductory questions about their previous academic history, students are asked questions intended to assess their general appreciation of fatigue, their understanding of the stress state associated with a stress concentration, and how stress concentrations influence static strength and fatigue life of structures. Results in each of these categories are presented here.

\section{General Appreciation of Importance of Fatigue}

Question 4 of the survey asks students to estimate the frequency of failure in aircraft structural components by estimating the percentage of failures resulting from overload, fatigue, corrosion, and wear/abrasion. These results are compared with the results reported by Findlay and Harrison ${ }^{1}$ based on a survey of engineering practice in Figure 6. For simplicity the number of categories was reduced from those included in Reference 1. Figure 6 shows that after completion of the aerospace structures and structures lab courses, students have a much more accurate understanding of the prevalence of fatigue in engineering practice than incoming students, though the role of 'overload' is still overestimated. To quantitatively evaluate the significance of this result, a chi-squared test was made based on the number of respondents who correctly identified fatigue as the most frequent cause of component failure. The null hypothesis was that the same proportions would be seen in the after group as in the before group. The $p$ value resulting from the chi-square test in this case was 0.0002 , thus indicating rejection of the null hypothesis and demonstrating a high degree of confidence that students in the 'after' group have a significantly enhanced understanding of the relative importance of fatigue compared to the 'before' group. It is not possible to assess how much this enhanced understanding is 
attributable to the lab experience as opposed to other instruction on fatigue that these students received, for example in lecture courses.

Students were given a list of examples of engineering failures and were asked to identify which were attributable to fatigue. Figure 7 shows that students who had completed the course sequence were much more able to correctly identify case studies of fatigue than students who had not. (Of those cases asked about, the de Havilland Comet and Aloha 243 examples are classic case studies in fatigue, while the rest are not associated with fatigue.) It should be noted that the Comet, Aloha 243 and Flight 587 case studies are discussed in the Design of Aerospace Structures course, which may account for some of the incorrect identification of Flight 587 in the After group. While the overall rates of recall are not high, it is clear that many students retained knowledge of some of the classic fatigue cases two semesters after studying them in class.

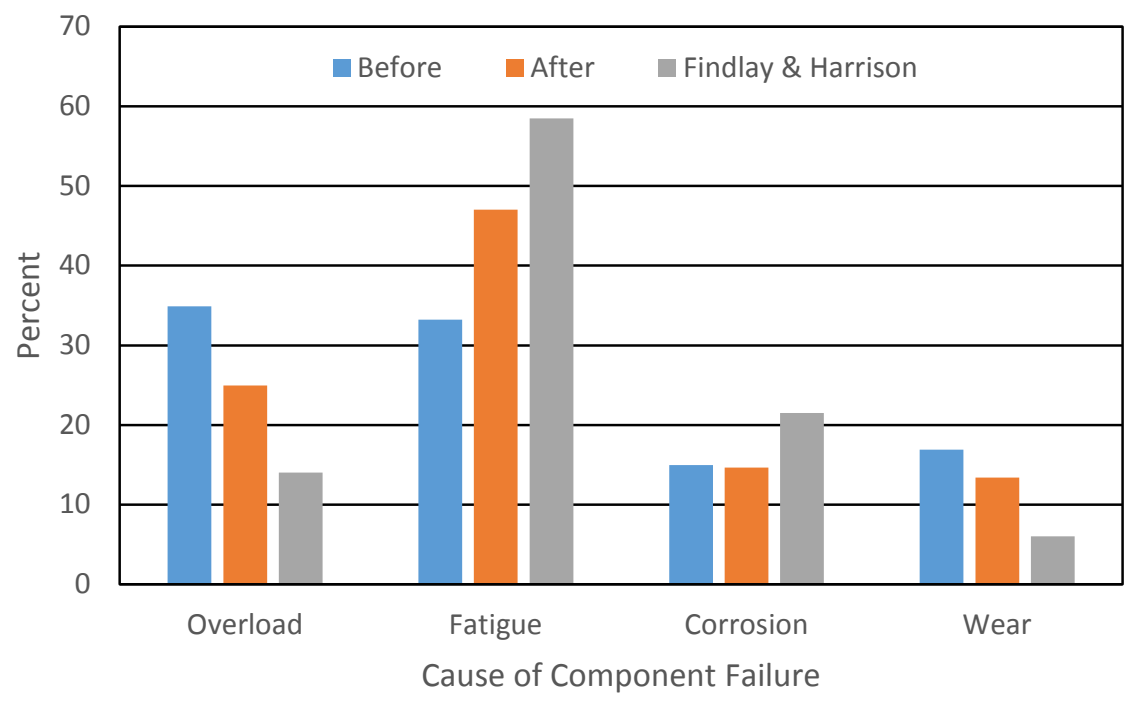

Figure 6: Comparison between student expectations of proportions of aircraft component structural failure and results from engineering practice reported by Findlay and Harrison. ${ }^{1}$

\section{Understanding of Stress State Resulting from Stress Concentration Effects}

A series of questions asks students to consider the case of a plate containing a circular hole, shown in Figure 8. Students are asked to identify the location of the maximum stress concentration and to answer questions about the state of stress resulting from the presence of the hole. Note that this geometry and loading is essentially similar to the stress concentration specimens used in the laboratory exercises that form the subject of this paper, though in the survey it is specified that the hole diameter is small compared to the plate width.

When asked to identify the location of the maximum stress in the specimen (Appendix B, question 7a) students in the 'Before' group largely avoided the hole, with a majority choosing point D. After the lecture/lab experience focusing on stress concentrations, almost 70\% correctly identified point B as the location of maximum stress concentration. This is shown in Figure 9. Comparing students in the 'before' and 'after' groups who answered this question correctly using 
the chi-squared test with a null hypothesis of no change from the 'before' group rates results in a $p$-value of $3.5 \times 10^{-9}$, thus demonstrating a very signification improvement of the understanding of stress concentration. The curious prevalence of choice $\mathrm{D}$ in the 'Before' group is difficult to understand but may result from a lack of appreciation of internal stress states in general.

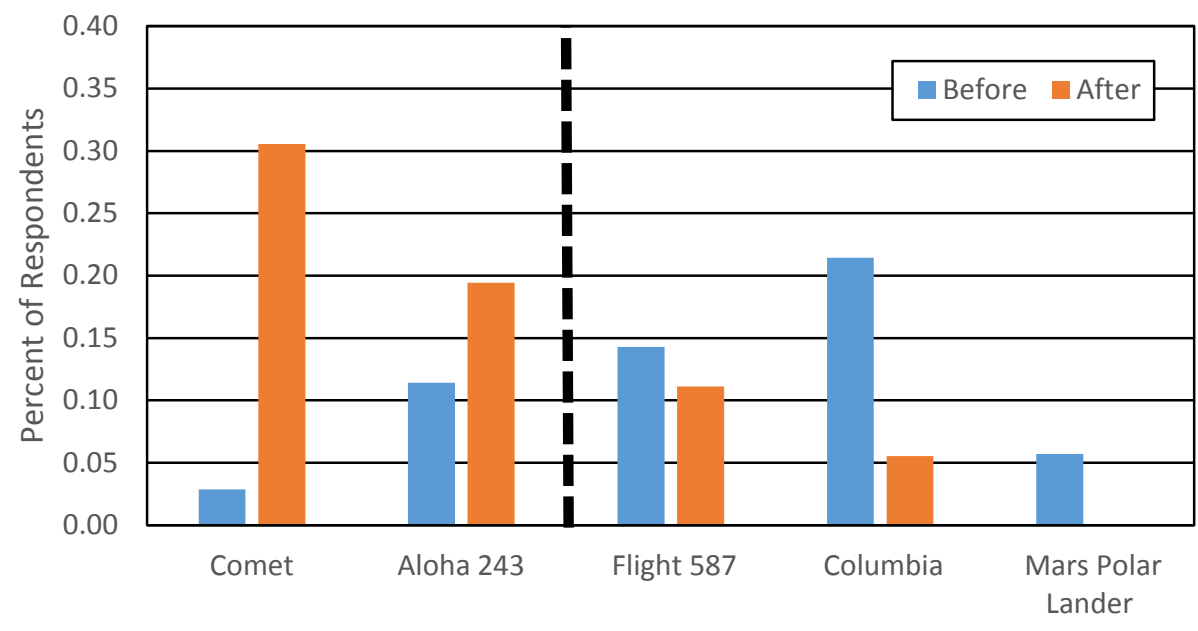

Example of Engineering Failure

Figure 7: Student identification of fatigue case studies. Cases to the left of the dashed line are classic examples of fatigue failures, cases to the right of the dashed line are engineering failures unrelated to fatigue.

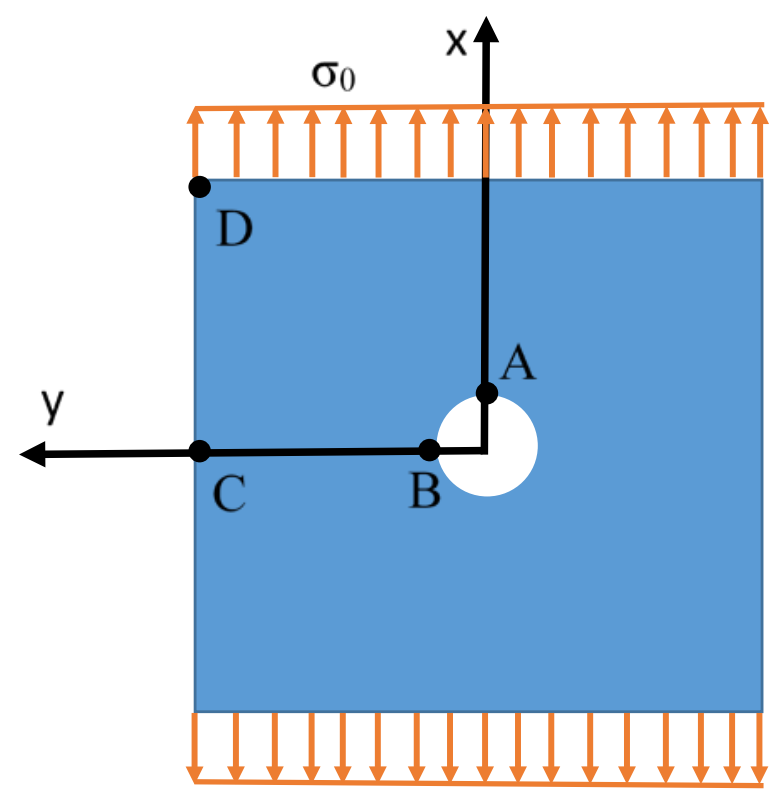

$\sigma_{0}$

Figure 8: Geometry of plate with hole forming basis of survey questions pertaining to stress concentrations. 


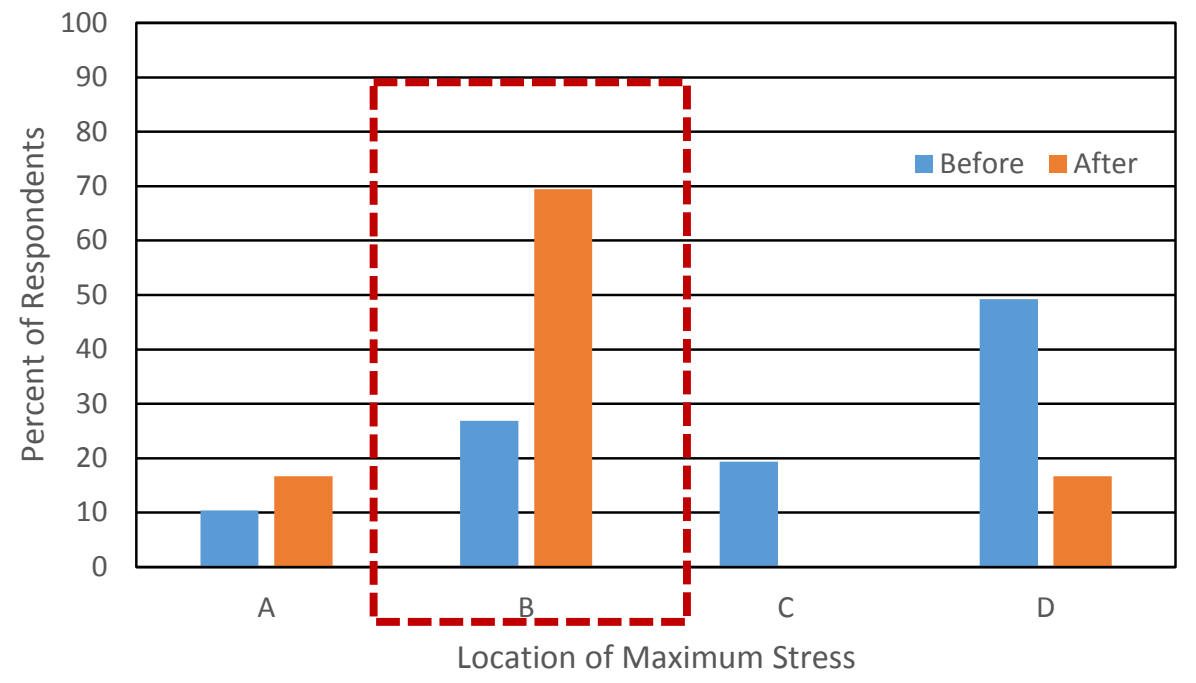

Figure 9: Identification of location of maximum stress concentration. (Correct answer enclosed in box)

The number of students correctly identifying the stress concentration factor for a wide plate as equaling 3 increased from 27\% to 39\% for those students who had completed the lab exercise. (the chi-squared test results in $p$-value of 0.09 based on null hypothesis of same rate as the 'before' group.) The rate of correctly identifying the stress at point $\mathrm{C}$ as equal to the far field stress increased from $32 \%$ to $67 \%$ from the before to after group (the chi-squared test results in $p$-value of $1 \times 10^{-5}$ based on null hypothesis of same rate as the 'before' group.). The most subtle aspect of the nature of the stress field around the circular hole asked about is the presence of compression stress that is found at point A. Only $9 \%$ of the "Before" group correctly identified that behavior, while $28 \%$ of the after group did (the chi-squared test results in $p$-value of $6 \times 10^{-5}$ based on null hypothesis of same rate as the 'before' group).

Overall, the results show that the students who had completed the laboratory exercises involving stress concentrations has a significantly better understanding of the nature of stress concentrations than students who had not completed the laboratory exercise and further that they retained this understanding despite the significant time lag between the time when the experiment was conducted and when the survey was taken. It is not possible to assess whether this improvement is due solely to the lab experiment or was influenced by other causes.

\section{Comparison between Static Strength and Fatigue Life}

Students were asked to identify factors that would contribute to the static and fatigue life of ductile metal test specimens from among the choices of heat treatment, surface polishing, surface scratches, or surface paint. While only the heat treatment would be a significant factor in the quasistatic test (stress concentrations associated with surface finish would be alleviated by ductility), the surface finish factors of polishing and scratching can negatively impact fatigue crack initiation and thus fatigue life. This effect on fatigue life addresses points raised in the 
fatigue experiment described above, and thus it was hoped that the cohort of students in the 'after' group would more accurately identify significant factors in static and fatigue life. Figure 10 shows results of these survey questions. Students in the 'after' group performed better at identifying the relative importance of surface finish for each loading condition. Strangely, students in the 'after' group had a reduced impression of the importance of heat treatment with regard to fatigue behavior.

Chi-squared tests were done for each specimen modification individually based on a null hypothesis of no change in response rate from the 'before' group. For quasistatic loading, the $p$ values were $0.004,0.12,0.19$ and 0.07 for heat treating, polishing, scratches, and painting, respectively. For fatigue loading, the $p$-values are $0.006,0.97,0.04$ and 0.002 for the same categories. Thus we see that for quasistatic loading the only changes significant at a $90 \%$ confidence level are in assessing the relevance of heat treatment and paint, while in fatigue loadings, all modifications except polishing show significant changes at the $90 \%$ confidence level. In all cases except assessing the importance of heat treatment there is a trend toward improved understanding between the 'before' and 'after' groups. Why there is a decrease in understanding of the role of heat treatment is a question that warrants further investigation.
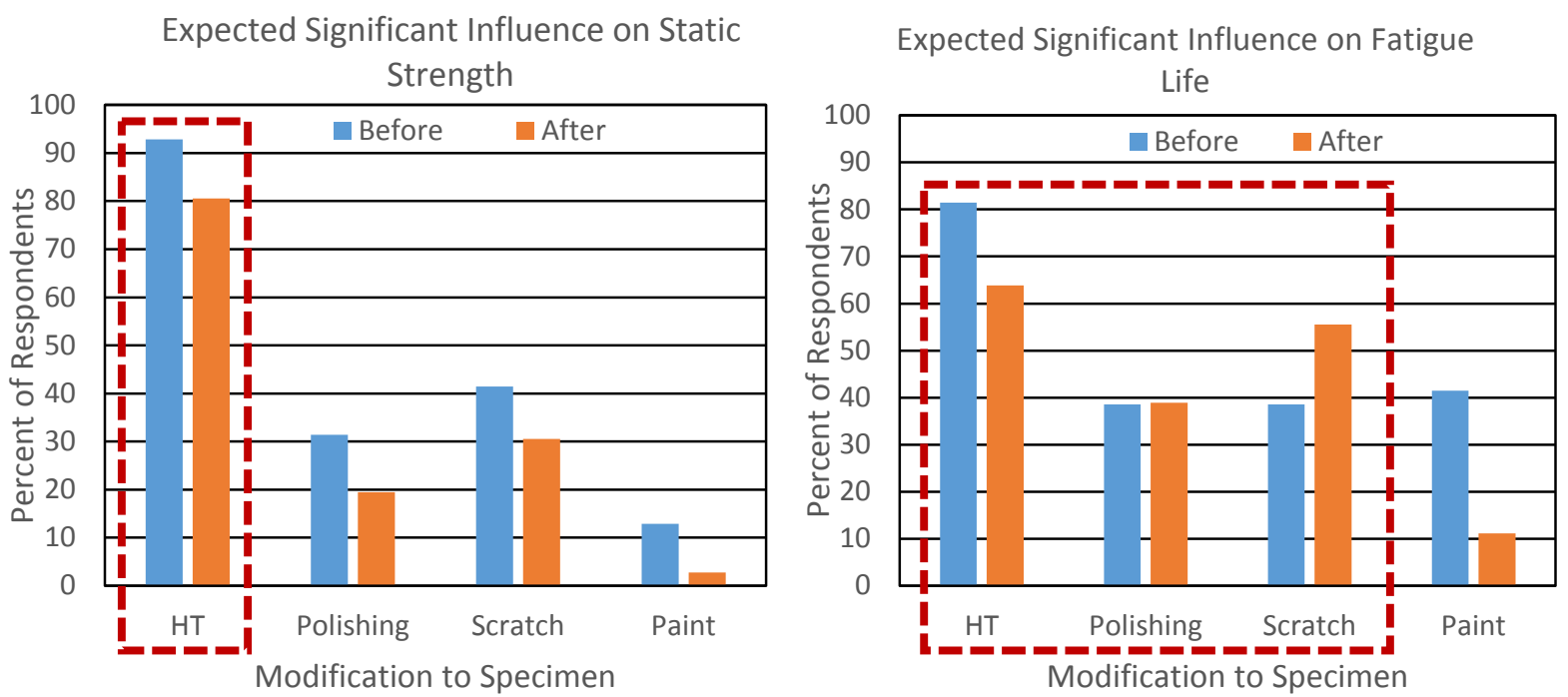

Figure 10: Identification of factors in static and fatigue strength. (Correct answers in boxes)

As a final check as to whether students who have completed the laboratory exercise described in this paper, students in the survey were asked to qualitatively predict the results of hypothetical quasistatic and fatigue experiments in which specimens with and without stress concentrations are compared (See Question 8a and 8b in Appendix B). These hypothetical experiments are qualitatively the same as the experiments conducted above, but the loading condition and the nature of the stress concentrations is different. For the quasistatic example, due to plasticity effects, the presence of the hole should produce only a slight weakening effect, due to the reduction in cross-section area. Students who overestimate the significance of the stress concentration effect in quasistatic loading would incorrectly expect beam A to be much stronger. 
In the fatigue case, experience in the lab should demonstrate that stress concentration effects are highly significant in reducing fatigue life, resulting in a much longer life for beam A. Results from this question is shown in Figure 11. Results show that the 'after' group was less accurate in predicting the quasistatic strength, but were somewhat more accurate in predicting the effect on fatigue life. A possible reason for this is that the students' increased awareness of stress concentrations, as demonstrated by the other survey results, clouded their thinking, making them lose sight of the role of plasticity in the quasistatic case. Chi-square tests result in $p$-values of 0.23 and 0.37 for the quasistatic and fatigue cases, respectively, based on a null hypothesis of no improvement from the 'before' results. Thus these comparisons do not demonstrate a significant change at the $90 \%$ confidence level.

\section{Conclusion}

A sequence of laboratory experiments for upper level aerospace engineering students that emphasizes stress concentrations and their role in quasistatic and fatigue loading is described. The fatigue experiment can be conducted with a servohydraulic testing machine using specimens that are very simple to produce. The fatigue experiment fills the need of emphasizing the significance of fatigue in aerospace structural design. Similar experiments could be duplicated at most engineering universities, enhancing the undergraduate education in this important topic that is sometimes overlooked at the undergraduate level.

A survey of students taken before and after completing the course shows that graduates of the course have a significantly improved understanding the stress concentration effects and their influence on the stress field. These students also have a significantly increased awareness of the importance of fatigue in engineering practice. Their appreciation of the role of stress concentrations on overall fatigue life, while possibly improved over the students entering upper level aerospace structures courses, shows that future improvement is warranted to help the students understand and retain knowledge learned in this area.
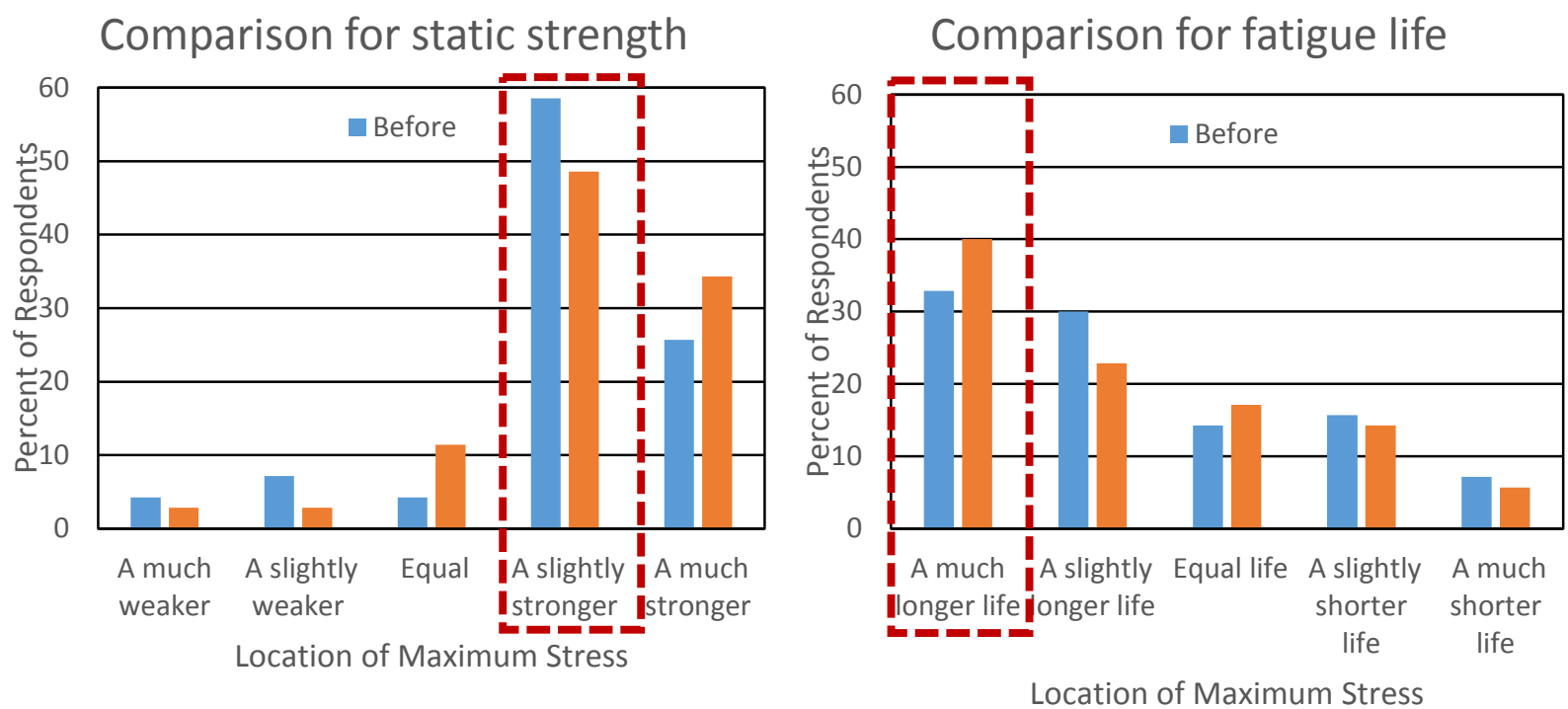

Figure 11: Predictions of hypothetical quasistatic and fatigue tests. (Correct answers in boxes) 


\section{References}

1. Findlay, S. J., and N. D. Harrison, "Why Aircraft Fail,” Materials Today, Vol. 5, No. 11, November 2002, pp. 18-25.

2. Curtis, H. D., Fundamentals of Aircraft Structural Analysis, Irwin, Chicago, 1997.

3. Bibel, G. Beyond the Black Box, The Forensics of Airplane Crashes, Johns Hopkins University Press, Baltimore, 2008.

4. Wignall, W. United States Air Force Aircraft Accident Investigation Board Report F-15C S/N 80-0034, Report No. 2007102KSTL002A, 2008. URL:http://www.acc.af.mil/shared/media/document/AFD-080110-017.pdf

5. “National Transportation Safety Board Aviation Accident Database \& Synopses” [online] URL: http://www.ntsb.gov/_layouts/ntsb.aviation/index.aspx

6. ASTM Standard E8/E8M-15a, "Standard Test Methods for Tension Testing of Metallic Materials," ASTM, West Conshohocken, PA, 2015.

7. Experimental Stress Analysis Notebook, Issue 10, April 1989, Vishay Measurements Group, Raleigh, NC.

8. Beer, F. P, Johnston, E. R. Jr., DeWolf, J. T., and D. F. Mazurek, Mechanics of Materials, $7^{\text {th }}$ ed., Mc-Graw Hill, New York, 2015, pp. 117-122.

9. ASTM Standard E466-15, "Standard Practice for Conducting Force Controlled Constant Amplitude Axial Fatigue Tests of Metallic Materials," ASTM, West Conshohocken, PA, 2015.

10. MTS Systems Corporation, "810 Performance Curves,” MTS Document 100-154-137, MTS, Eden Prairie, MN, 2006.

11. Fink, A., How to Conduct Surveys, Sage Publications, Thousand Oaks, CA, 2006.

12. Gere, J. M. and B. J. Goodno, Mechanics of Materials, $7^{\text {th }}$ ed.,Cengage, 2009.

13. Hibbeler, R. C., Mechanics of Materials, $7^{\text {th }}$ ed., Pearson Prentice Hall, Upper Saddle River, NJ, 2008.

14. Allen,D. H., and W. E. Haisler, Introduction to Aerospace Structural Analysis, Wiley, New York, 1985.

15. Donaldson, B. K., Analysis of Aircraft Structures An Introduction, $2^{\text {nd }}$ ed., Cambridge University Press, Cambridge, 2008.

16. Megson, T. H. G., Aircraft Structures for Engineering Students, $5^{\text {th }}$ ed., Butterworth-Heinemann, Oxford, 2013.

17. Sun, C. T., Mechanics of Aircraft Structures, $2^{\text {nd }}$ ed., Wiley, New York, 2006. 


\section{Appendix A}

Table A1: Quantity of coverage of fatigue and fracture topics in selected Mechanics of Materials and Aerospace Structures textbooks

\begin{tabular}{|c|c|c|c|c|}
\hline Authors & Title & $\begin{array}{l}\text { Number of Pages } \\
\text { of } \\
\text { Fatigue/Fracture } \\
\text { Content }\end{array}$ & $\begin{array}{l}\text { Total Pages } \\
\text { (not including } \\
\text { appendixes) }\end{array}$ & $\begin{array}{l}\text { Summary of fatigue/fracture } \\
\text { coverage }\end{array}$ \\
\hline \multicolumn{5}{|c|}{ Mechanics of Materials Texts } \\
\hline $\begin{array}{l}\text { Beer, Johnston, } \\
\text { DeWolf and } \\
\text { Mazurek }^{8} \\
\end{array}$ & $\begin{array}{l}\text { Mechanics of } \\
\text { Materials, 7/e }\end{array}$ & 1.5 & 831 & - $\quad$ Description of S-N diagram \\
\hline $\begin{array}{l}\text { Gere and } \\
\text { Goodno }^{12}\end{array}$ & $\begin{array}{l}\text { Mechanics of } \\
\text { Materials, 7/e }\end{array}$ & 2.5 & 942 & - $\quad$ Description of S-N diagram \\
\hline Hibbeler $^{13}$ & $\begin{array}{l}\text { Mechanics of } \\
\text { Materials, 7/e }\end{array}$ & $<2$ & 829 & $\begin{array}{ll}- & \text { Description of S-N diagram } \\
\text { - } & \text { Mention of importance with } \\
\text { respect to stress } \\
\text { concentrations }\end{array}$ \\
\hline \multicolumn{5}{|c|}{ Aerospace Structures Texts } \\
\hline $\begin{array}{l}\text { Allen and } \\
\text { Haisler }^{14}\end{array}$ & $\begin{array}{l}\text { Introduction to } \\
\text { Aerospace } \\
\text { Structural } \\
\text { Analysis }\end{array}$ & 0 & 480 & - $\quad$ None \\
\hline Curtis $^{2}$ & $\begin{array}{l}\text { Fundamentals of } \\
\text { Aircraft Structural } \\
\text { Analysis }\end{array}$ & 17 & 789 & $\begin{array}{ll} & \text { Review of historical } \\
& \text { examples involving fatigue } \\
\text { - } & \text { S-N diagrams } \\
\text { - } & \text { Relevance of stress } \\
& \text { concentrations } \\
\text { - } & \text { Miner's Rule } \\
\text { - } & \text { Fracture mechanics basics } \\
\text { - } & \text { Paris law }\end{array}$ \\
\hline Donaldson $^{15}$ & $\begin{array}{l}\text { Analysis of } \\
\text { Aircraft } \\
\text { Structures, 2/e }\end{array}$ & 9 & 837 & $\begin{array}{ll}\text { - } & \text { S-N diagrams } \\
\text { - } & \text { Miner's rule } \\
\text { - } & \text { Relevance of stress } \\
& \text { concentrations }\end{array}$ \\
\hline Megson $^{16}$ & $\begin{array}{l}\text { Aircraft Structures } \\
\text { for Engineering } \\
\text { Students, 5/e }\end{array}$ & 25 & 823 & $\begin{array}{ll}\text { - } & \text { S-N diagrams } \\
\text { - } & \text { Miner’s rule } \\
\text { - } & \text { Design against fatigue } \\
\text { - } & \text { Goodman relation } \\
\text { - } & \text { Fracture mechanics basics } \\
\text { - } & \text { Paris law } \\
\end{array}$ \\
\hline Sun $^{17}$ & $\begin{array}{l}\text { Mechanics of } \\
\text { Aircraft } \\
\text { Structures, 2/e }\end{array}$ & 25.5 & 293 & $\begin{array}{ll}\text { - } & \text { Fracture mechanics basics } \\
\text { - } & \text { Relevance of stress } \\
\text { - } & \text { Concentrations } \\
\text { - } & \text { Miner's rule } \\
\text { - } & \text { Paris law }\end{array}$ \\
\hline
\end{tabular}




\section{Appendix B: Survey questions}

The following survey is administered as part of an effort to improve the aerospace structures curriculum. Participation in the survey is voluntary. If you do not wish to participate, simply check this box $\square$ and return the empty form. Survey results are anonymous and will not factor into your grades. Please do not use cell phones or computers.

1. What is your status regarding MAE 4281, Design of Aerospace Structures

Already Completed: Year taken

Currently Enrolled

Plan to Take in the Future

No plan to take MAE 4281

2. What is your status regarding MAE 4284, Aerospace Structures Laboratory

Already Completed: Year taken

$\square$ Currently Enrolled

Plan to Take in the Future

No plan to take MAE 4284

3. In which of the following courses was the topic of (metal) fatigue addressed? (Check all that apply.)

If you did not take a course, cross it out.

$\square$ CHE 3260 Materials Science and Engineering

CHE 3265 Materials Laboratory

MAE 1201 Introduction to Aerospace Engineering

MAE 2081Applied Mechanics: Statics

MAE 3083 Mechanics of Materials

4. The most common causes of failure in aircraft structural components are listed below.

Estimate the percentage of failures resulting from each cause. Try to make sure the answers add up to $100 \%$

Overload (due to extreme weather conditions, pilot error, design mistake, etc.)

Fatigue (due to cyclic loads)

Corrosion

Wear/abrasion

5a. In a lab test, a metallic circular shaft is to be loaded in torsion slowly until failure. Which of the following may significantly influence the maximum torque that the shaft supports? (check all that apply):

$\square$ Change in heat treatment of the metal

Polishing the edges of the material

Scratching the edge of the material with an $\mathrm{x}$-acto blade

Painting the surface of the material 
5b. In a lab test, a metallic circular shaft is to be loaded cyclically (repeatedly) in torsion. Which of the following may significantly influence the number of cycles before failure (fatigue life)?

(check all that apply):

$\square$ Change in heat treatment of the metal

$\square$ Polishing the edges of the material

$\square$ Scratching the edge of the material with an $\mathrm{x}$-acto blade

$\square$ Painting the surface of the material

6. Each of the following represents a well-known example of engineering failure. In which of these cases are you confident that fatigue was a significant factor? (Please don't just guess. If you are not do not have any knowledge about a given case, leave it unchecked.)

$\square$ Early crashes of the de Havilland Comet Airliner

Flight 587, crash of an Airbus A300 near New York City in 2011

Aloha Airlines flight 243 incident involving a Boeing 737

The Space Shuttle Columbia Disaster

Loss of the Mars Polar Lander spacecraft

7. Consider a metallic plate loaded in tension with stress $\sigma_{0}$ as shown in picture. A circular hole is located at the center of the plate. The plate is very wide compared to the hole diameter.

a) At which of the following points will the magnitude of the normal stress be greatest?

$\square$ A

$\square \mathrm{B}$

C

$\mathrm{D}$

b) Estimate the value of normal stress at point $B$

$\square 9 \sigma_{0}$

$\square 3 \sigma_{0}$

$\square 1.5 \sigma_{0}$

$\square \sigma_{0}$

$\square 0$

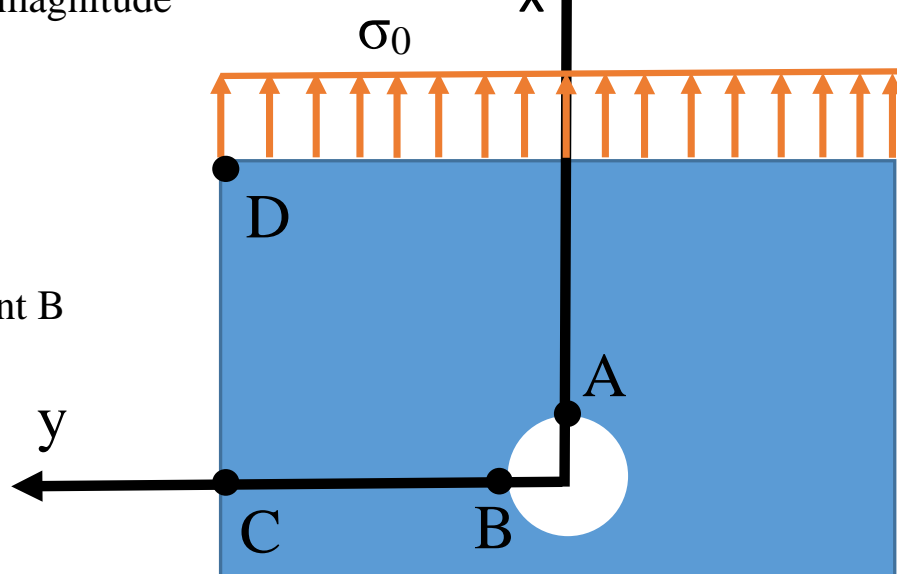

c) Estimate the value of normal stress at point $\mathrm{C}$

$\square 9 \sigma_{0}$

$\square 3 \sigma_{0}$

$1.5 \sigma_{0}$

$\square \sigma_{0}$

$\square 0$

d) Which of the following best describes the state of stress at point A $\sigma_{0}$

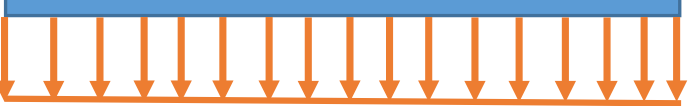

$\square$ There is no stress at point $A$

There is a small tensile stress in the $\mathrm{x}$-direction at point $\mathrm{A}$

There is a tensile stress in the $y$-direction at point $A$

$\square$ There is a compression stress in the y-direction at point $\mathrm{A}$ 
8a. Imagine the following experiment:
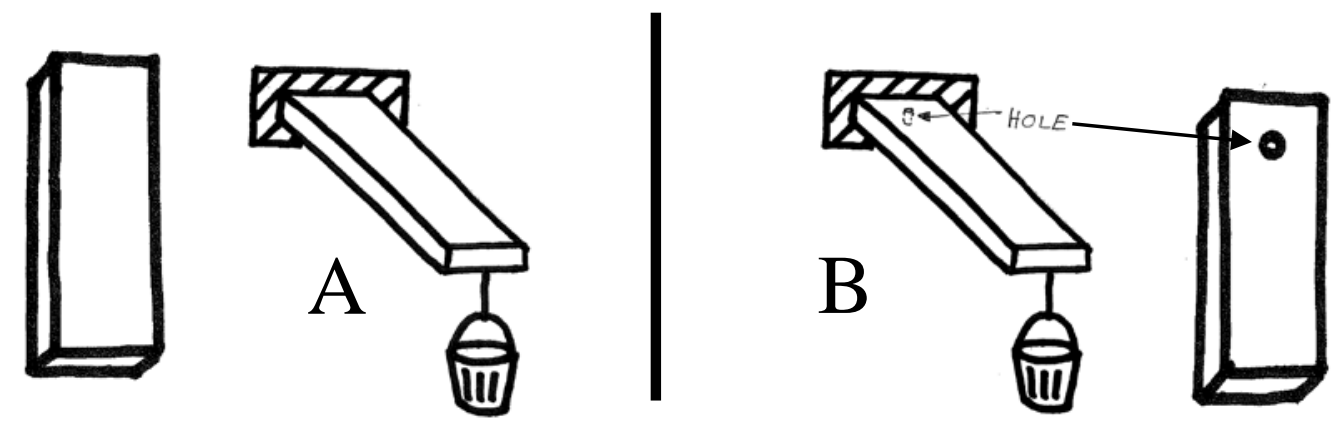

Two beams made of a ductile metal are cantilevered to a wall. The beams are identical except that beam B has a small hole drilled in it as shown. Load is slowly applied to each beam by filling the bucket attached to each beam with sand. Both buckets are filled at the same rate. Which of the following best describes the expected results of the experiment?

Beam A will fail much earlier than Beam B.

Beam A will fail a short time before Beam B.

$\square$ Beams A and B will fail at the same time.

Beam B will fail a short time before Beam A.

$\square$ Beam B will fail much earlier than Beam A.

8b. Imagine the following experiment:
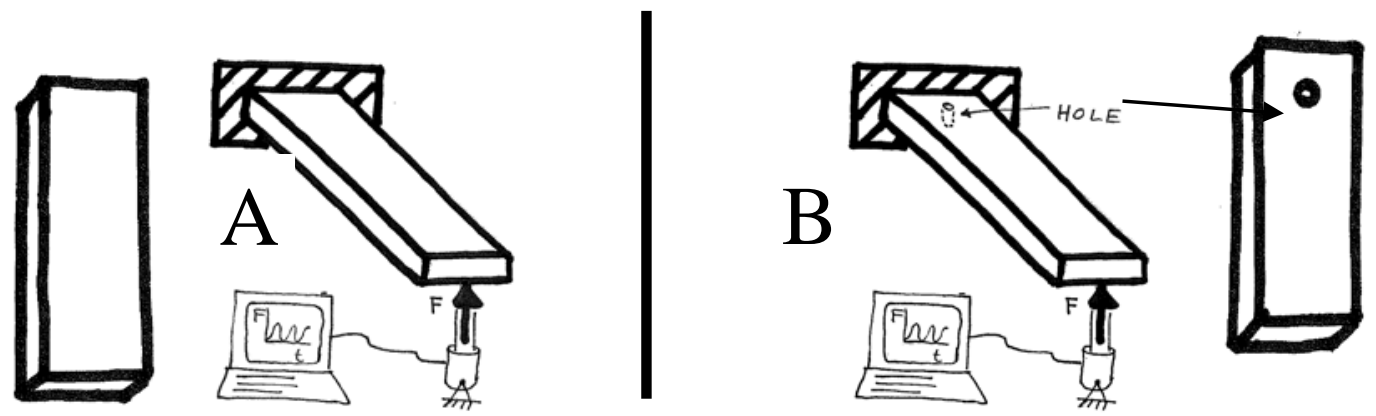

Two beams made of a ductile metal are cantilevered to a wall. The beams are identical except that beam B has a small hole drilled in it as shown. Equal loads are applied to each beam using hydraulic actuators acting under computer control. The load varies cyclically from zero to a maximum value (the maximum value is far less than the load required to break the beam) then back to zero. This load condition is repeated multiple times until the beam fails. Which of the following best describes the expected results of the experiment?

Beam A will endure many more cycles before failure than Beam B.

Beam A will endure a small number of more cycles before failure than Beam B.

Beams A and B will fail at approximately the same time.

Beam B will endure a small number of more cycles before failure than Beam A.

Beam B will endure many more cycles before failure than Beam A. 